\title{
TECCIENCIA
}

\section{Design and development of transcutaneous electrical stimulation equipment for neuromuscular rehabilitation in individuals with facial palsy[}

\section{Diseño y desarrollo de un equipo de estimulación eléctrica transcutanea para rehabilitación neuromuscular en personas con parálisis facial}

\author{
Jorge Eduardo Quintero $^{1 *}$, Gioanny Francisco Manotas $^{2}$, Yuber Alejandro Galeano ${ }^{3}$ \\ Diego Mauricio Tellez ${ }^{4}$ \\ ${ }^{1}$ Universidad de Santander (UDES) Santander, Colombia, jquintero@udes.edu.co \\ ${ }^{2}$ Universidad de Santander (UDES) Santander, Colombia, gmanotas@udes.edu.co \\ ${ }^{3}$ Universidad de Santander (UDES) Santander, Colombia, yuberku@ gmail.com \\ ${ }^{4}$ Universidad de Santander (UDES) Santander, Colombia, iegott44@hotmail.com
}

\begin{abstract}
Peripheral facial palsy is a relatively common pathology that is usually unilateral. Multiple causes generate it, producing aesthetic and functional deformity, as well as emotional, social, and professional alterations. We developed electronic equipment for transcutaneous electric stimulation, which will be applied in neuromuscular rehabilitation treatments of individuals who have suffered peripheral facial palsy. Electrotherapeutic energy is generated through current sources, whose waveforms consist of rectangular biphasic pulses, which can be adjusted in their duration or width, frequency, and intensity. For patient electrical safety, the equipment is powered with batteries. The waveforms generated and the therapeutic parameters are controlled through a microcontroller. What differentiates this equipment from the few found in the market, for this rather specific application, is that it was designed with four independent channels for passive therapy, which permits stimulating more than one neuromuscular package at the same time, and also has one channel for active therapy, which is dynamically applied by the therapist by moving the active electrode over the surface of the face.
\end{abstract}

Keywords: Faradic currents, electrotherapy, neuromuscular stimulation, facial palsy, biphasic pulses

\section{Resumen}

La parálisis facial periférica es una patología relativamente frecuente que habitualmente es unilateral. Las causas que la generan son múltiples, produciendo una deformidad estética y funcional, así como alteraciones emocionales, sociales y profesionales. Se ha desarrollado un equipo electrónico de estimulación eléctrica transcutánea, que se aplicará en tratamientos de rehabilitación neuromuscular de personas que han sufrido parálisis facial periférica. La energía electroterapéutica se genera mediante fuentes de corriente, cuyas formas de onda consisten en pulsos bifásicos rectangulares, a los cuales se les puede ajustar la duración o ancho del mismo, la frecuencia y la intensidad. Por seguridad eléctrica para el paciente el equipo se alimenta con baterías. Las formas de onda que se generan y los parámetros terapéuticos se controlan mediante un microcontrolador. Lo que diferencia a este equipo de los pocos que se encuentran en el mercado, para esta aplicación tan específica, es que se diseñó con cuatro canales independientes para terapia pasiva, permitiéndole estimular más de un paquete neuromuscular al mismo tiempo, y dispone también de un canal para terapia activa, que lo aplica dinámicamente el terapeuta al mover el electrodo activo por la superficie de la cara.

Palabras clave: Corrientes farádicas, electroterapia, estimulación neuromuscular, parálisis facial, pulsos bifásicos 


\section{TECCIENCIA}

\section{Introduction}

The initiative for this technological development project emerges from the need to optimize the rehabilitation process in patients with facial palsy, in the facilities of the Neurotrauma Center in Bucaramanga (Colombia), which is a center specialized in neurorehabilitation [1]. The project was carried out at the Research Center for Development and Innovation on Rehabilitation Engineering (CIDi IngeRehab), ascribed to the Neurotrauma Center, whose mission is that of producing high added value technologies at low costs to improve the quality of life of handicapped individuals [2]. An interinstitutional cooperation agreement was ratified, where Universidad de Santander (UdeS) provides research professors, who are in charge of the management and technological development and the Neurotrauma Center assumes the costs of its materials. These types of $R \& D$ projects satisfy a real need of the entrepreneurial world, in this case, an entity from the Colombian health sector. Research entrepreneurship was addressed by integrating health disciplines specialized in this type of physical rehabilitation (Physical therapy and Speech therapy), Electronic Engineering, and Industrial Design, highlighted because of their interdisciplinary nature. It was necessary to construct this facial electrostimulator prototype, given that the market only offers electrostimulation equipment for facial aesthetics of antiwrinkle rejuvenation and no models are found for clinical applications.

Rehabilitation engineering may be defined as "the branch of engineering destined to research, design, develop, implement, or adapt technological tools aimed at improving the quality of life of handicapped individuals or of those who require rehabilitation [3]. Rehabilitation engineers require basic knowledge of electric, electronic, and mechanical engineering, as well as medicine in anatomy, physiology, biomechanics, neuroscience, and kinesiology and must be able to communicate with other rehabilitation professionals like physiatrists, neurologists, and therapists (physical therapists, occupational therapists, speech therapists, and neuropsychologists) [3] Figure 1 shows technology developed under the concept of rehabilitation engineering, used in a patient's gait rehabilitation.

Figure 2 shows the specialized areas involved in a Rehabilitation Engineering R\&D project from which it can be concluded that it is a field of multidisciplinary technological development [5]. The current frontier of knowledge in Rehabilitation Engineering is focused on neuroengineering, which seeks to control directly with the brain prosthesis and technology for disability [6]

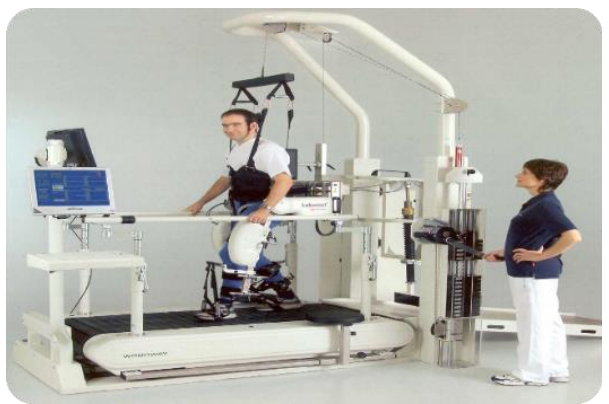

Figure 1. Technology developed by Rehabilitation Engineering Source: http://www.healingtherapies.info/treadmill_training.htm

Areas involved in a Rehabilitation engineering project

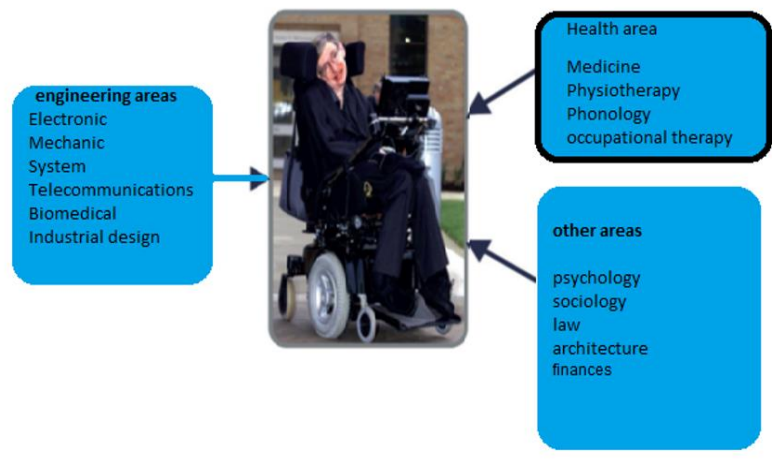

Figure 2. Areas involved in a Rehabilitation Engineering project Source: Authors

The development of the project introduced in this scientific article saw the intervention of two engineers and an electronics student, as well as an industrial design student; from the health sciences, a physical therapist and a speech therapist participated.

The CIDi - IngeRehab's mission is that of producing low cost, high added value technologies to improve the quality of life of handicapped individuals. Now, the vision projected is to become an interdisciplinary center, leading at the national and international levels in the production of technologies for the handicapped through research and innovation [2]

Moving on to the medical field, it is known that facial palsy is provoked by a lesion of the facial nerve, as shown on Figure 3 (yellow branches). The facial nerve is one of the 12 nerves joined directly to the brain and it contains sensitive and motor fibers. It specially controls the movements of the muscles of the face, closing of the eyes and mouth, secretion 


\section{TECCIENCIA}

of tears and saliva, and a part of the senses of taste. In some diseases, this nerve does not permit transmitting information from the brain to zones it controls, or vise versa; therein, resulting in facial palsy of which two types exist: central palsy and peripheral palsy [7]

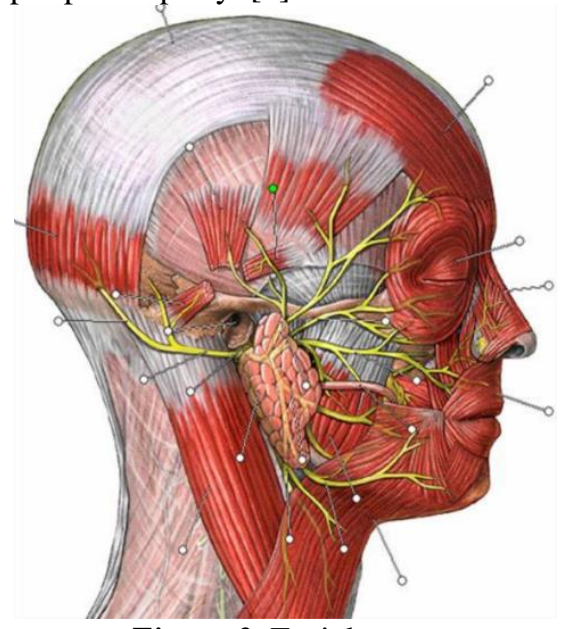

Figure 3. Facial nerve

Source:

http://groups.msn.com/recursoslogopedicos/distona.msnw

Central facial palsy is due to the interruption of the nerve fibers that unite the brain cortex to the nucleus of the facial nerve. It affects the part of the face on the opposite side of the lesion. It is characterized by palsy of half of the face in its lower half (respecting the eyelids and the forehead); it tends to affect the muscles of the cheek and of the contours of the mouth. Central facial palsy can have numerous causes; the most frequent being a lesion produced by a cerebral vascular accident (stroke). Figure 4 shows a case of central facial palsy where the patient is closing the eyes.

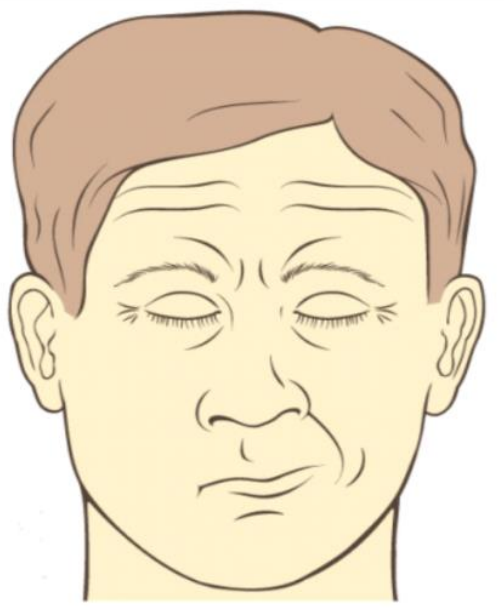

Figure 4. Central facial palsy Source:

http://www.gastromerida.com/secciones/semiologia/neurol ogico/septimopar.html
Peripheral facial palsy is also known as Bell's palsy. It occurs on the side of the face where the nerve lesion has taken place and it is characterized by asymmetry of the face when at rest, with features deviated toward the normal side. On the affected side, the face lacks expression, the corner of the lips and the wrinkles on the forehead are fallen; the lips appear slightly open. In some cases, secretion of saliva and tears diminishes on the affected side. The patient has difficulty eating and speaking, given the paralysis of the face muscles. Figure 5 shows a case of peripheral facial palsy where the patient is closing the eyes.

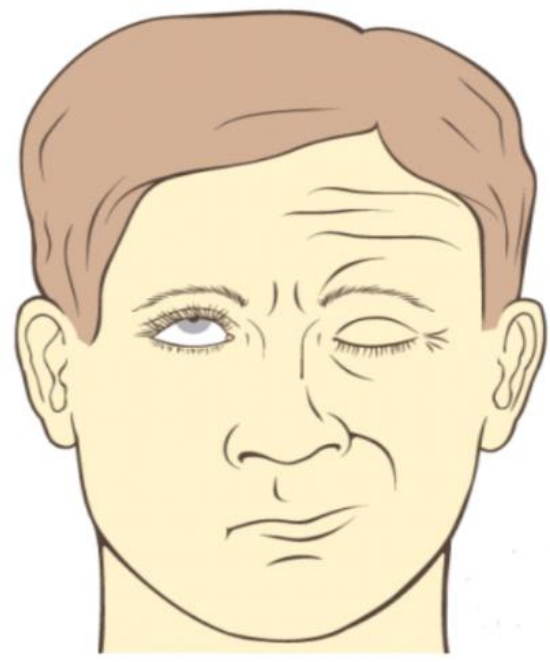

Figure 5. Peripheral facial palsy Source:

http://www.gastromerida.com/secciones/semiologia/neurol ogico/septimopar.html

Treatment for peripheral facial palsy, which is the most disabling of the two facial palsies, as well as the one with the highest occurrence, sometimes includes medications, but it is not clear how much they help. Corticosteroids (prednisone) tend to reduce swelling around the facial nerve and antiviral medications (acyclovir) may combat the virus that can be causing Bell's palsy [8], [9]

Also, Paula et al., (1998) [10]conclude that peripheral facial palsy managed with faradic electrostimulation shows higher complete functional recovery in less time, compared to pharmaceutical treatment with prednisone. From the aforementioned, a functional prototype was constructed of transcutaneous electric stimulation equipment for neuromuscular rehabilitation in individuals with facial palsy, which was denominated StimFace, to test the effectiveness and efficiency of electrotherapy on these types of treatments. 


\section{Materials and methods}

\subsection{Determination of design conditions of the transcutaneous electrical stimulation equipment for neuromuscular rehabilitation in individuals with facial palsy}

A meeting with the staff of therapists specialized in neurorehabilitation from the Neurotrauma Center established the conditions the transcutaneous electric stimulation equipment needed to fulfill for neuromuscular rehabilitation of individuals with facial palsy:

- Four e electrostimulation channels, with intensity control of independent current, to work on various muscles of the face at the same time, if necessary under extreme cases.

- Stimulation with current sources and not tension, for the current intensity not to depend on the patient's impedance measured between each pair of electrodes.

- The waveform of the stimulation current should be biphasic symmetry of pulses for its average value to be zero and for it not to produce electrochemical reactions under the electrodes due to galvanic effects [11]

- The maximum peak-to-peak stimulation current is 60 $\mathrm{mA}$ to avoid possible muscular tetanization produced by large current intensities.

- That the pulse width of the stimulation current (Phase Control) can be adjusted from 100 to $300 \mu \mathrm{S}$, at the start of the therapy.

- That the amount of pulses per second required can be adjusted, at the start of the therapy, between 20 and 200 pulses per second.

- Be able to adjust the ON/OFF characteristic of the pulse trains (faradic currents). Two options 4/12 seconds and $10 / 20$ seconds, for the passive therapy option [12]

- Have the option to select between passive therapy (the four channels) and active therapy (only channel one)

- Be able to select the time of the therapy session between 5,10 , and 15 minutes, respectively

- Show on the screen the therapeutic parameters determined by the specialist in physical rehabilitation, to keep a record of these during each therapy session.

\subsection{Block diagram and design of the prototype equipment to construct}

Based on the, previously mentioned, operating conditions of the equipment, a prototype equipment was designed according to the block diagram shown in Figure 6.

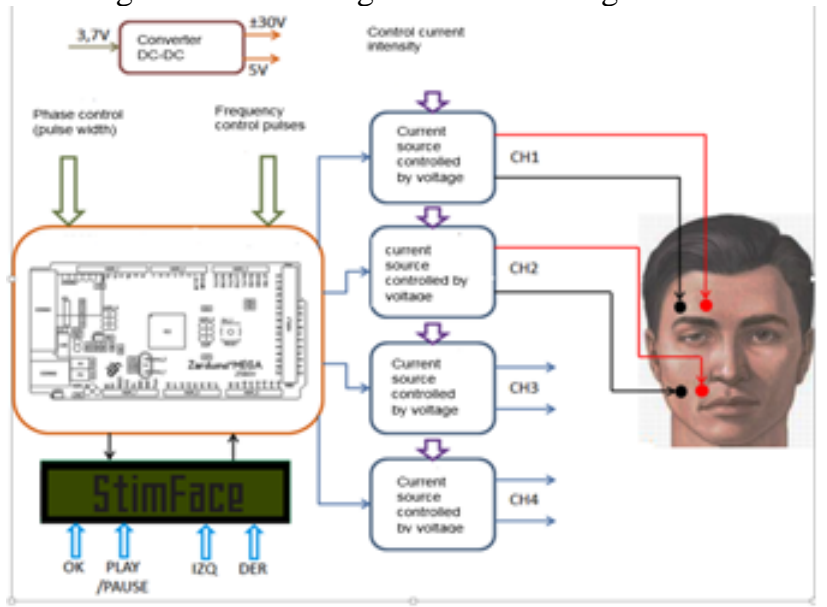

Figure 6. Block diagram of prototype equipment Source: Authors

An Arduino Mega 2560 microcontroller [13] was used. From there, the control waves are generated of the current sources applied to the patient's face. Pulse width is adjusted through an analog potentiometer connected to an analog input pin of the microcontroller, where $0 \mathrm{~V}$ corresponds to $100 \mu \mathrm{S}$ and $5 \mathrm{~V}$ to $300 \mu \mathrm{S}$. On the front panel of the equipment this will be marked as PHASE. A second analog potentiometer, connected to another analog input pin, permits adjusting the required amount of pulses per second, where $0 \mathrm{~V}$ corresponds to 20 pulses per second and $5 \mathrm{~V}$ to 200 pulses per second. On the front panel of the equipment this will be marked as frequency.

A program was developed on the microcontroller, which upon turning on the equipment runs the following routine: first, we can select between passive therapy (available on the four channels), which uses circular electrodes adhered to the face, and active therapy (available only on channel one), which uses a circular electrode adhered to the face and the other pen-type electrode, which the therapist displaces manually over the points on the face that require dynamic stimulation. The selection is made with the knobs normally open marked IZQ and DER, respectively, located on the front panel of the equipment and connected to the LCD control pins. Upon selecting the type of therapy, inform the microcontroller by pressing the knob $\mathrm{OK}$, connected to another LCD control pin. Second, if selecting passive therapy, we can now activate the channels required, by pressing the knob DER and then OK. Third, now we can determine the on/off time ratio of the pulse train that will be 


\section{TECCIENCIA}

applied, given that we are working with the concept of faradic currents [3]; two options, 4/12 seconds and 10/20 seconds, are available that are selected with knobs IZQ/DER-OK. Fourth, select the therapy duration time; three options are shown: 5, 10, and 15 minutes, which are selected with knobs IZQ/DER-OK. Fifth, press the knob PLAY/PAUSE to start the electrotherapy.

Once the therapy has started, by pressing PLAY/PAUSE the equipment will not deliver current to the patient, it remains on standby, until again pressing PLAY. If it is pressed two consecutive times, it is reinitiated and must be reset. If selecting active therapy, the following step is to determine its duration time, given that for this case through channel one continuous pulse wave is generated and not pulse train.

While the therapy session is taking place, the screen shows the type of therapy chosen, the active channels, duration of the Phase (pulse width), pulse frequency, characteristics of the pulse train (Ton/Toff), and duration of the therapy.

A DC converter - DC elevator was designed, given that because of electrical safety for the patient the equipment is powered with a $3.7-\mathrm{V}$ rechargeable battery and the converter delivers tensions of $+5 \mathrm{~V}$ to power the microcontroller and the LCD screen and $\pm 30 \mathrm{~V}$ to power the current sources.

The current sources deliver biphasic pulses (+/-), with adjustable amplitude from 0 to $30 \mathrm{~mA}$ peak. High-tension operational amplifiers were used in modified differential amplifier configuration, $80 \mathrm{~V} / 50 \mathrm{~mA}$ (Texas Instruments, reference OPA452).

\section{Results}

Figure 7 shows an image of the prototype of the initial version constructed, which has been denominated StimFace. The equipment's front panel shows the four knobs (IZQDER-OK-PLAY/PAUSE) used in the set up of the electrotherapy parameters; the two pulse width control potentiometers (PHASE) and FREQUENCY, respectively; and the four potentiometers of stimulation current intensity control, with their respective outputs to connect the electrodes.

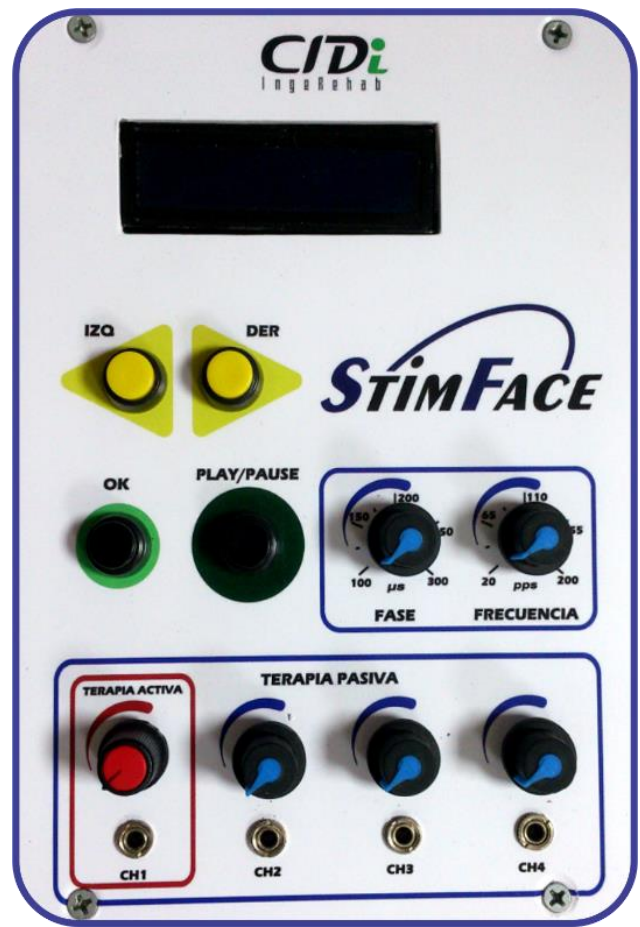

Figure 7. Functional model of the StimFace developed Source: Authors

The following shows the images taken of the oscilloscope on the output of channel 1 in passive therapy mode, with normalized load resistance in $1000-\Omega$ transcutaneous electrotherapy. Figure 8 shows the biphasic pulse with phase duration of $300 \mu \mathrm{S}$ and $20-\mathrm{V}$ amplitude, equivalent to an electrostimulation current of $40 \mathrm{~mA}$ peak to peak. Note that this type of wave does not have average value or DC. Figure 9 shows two continuous biphasic pulses with frequency of 200 pulses per second. Figure 10 shows the ON/OFF behavior characteristic of faradic currents; in this case, for a selection of $4 / 12$ seconds.

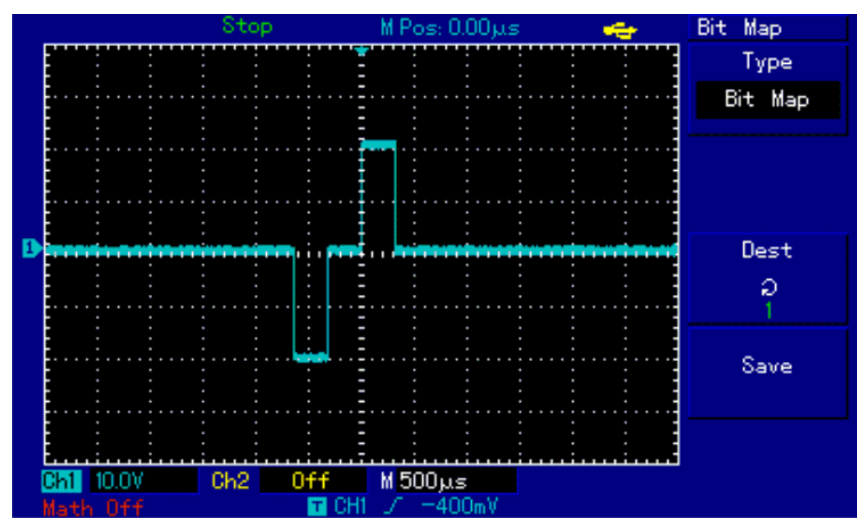

Figure 8. Biphasic pulse with $300 \mu \mathrm{S}$ width Source: Authors 


\section{TECCIENCIA}

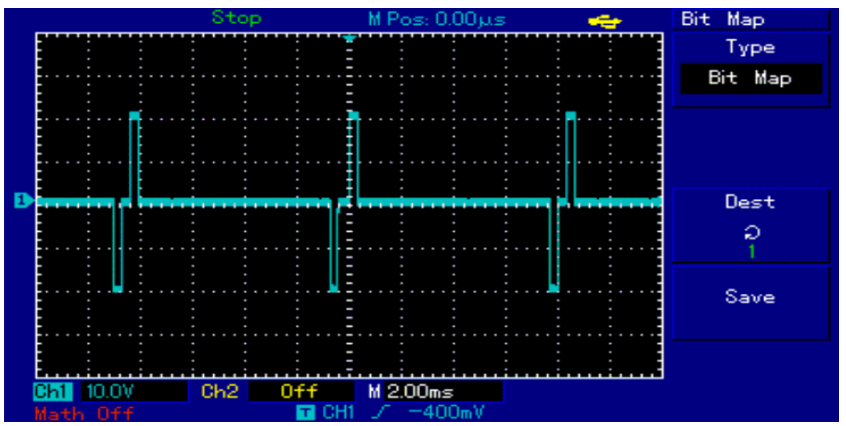

Figure 9. Biphasic pulses at frequency of 200 pulses per second

Source: Authors

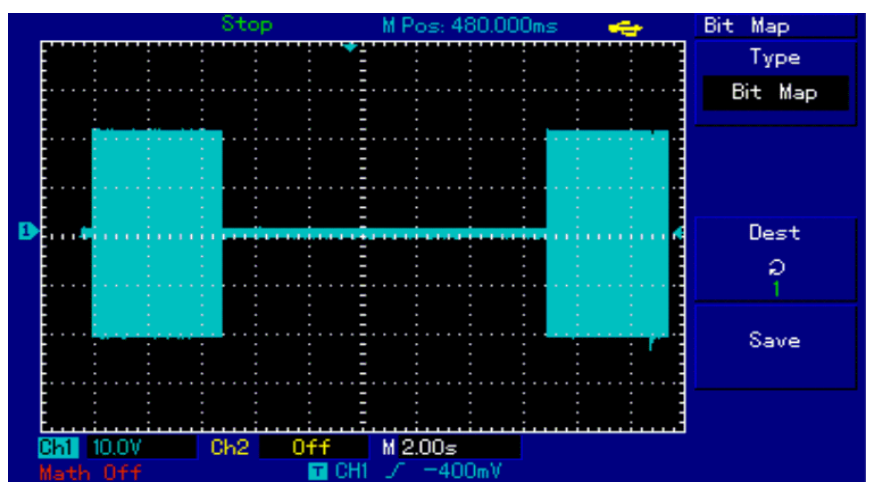

Figure 10. Biphasic pulse train with $4 / 12$ second Ton/Toff Source: Authors

Figure 11 shows the information deployed on the StimFace screen, as the therapy takes place, for therapist feedback.
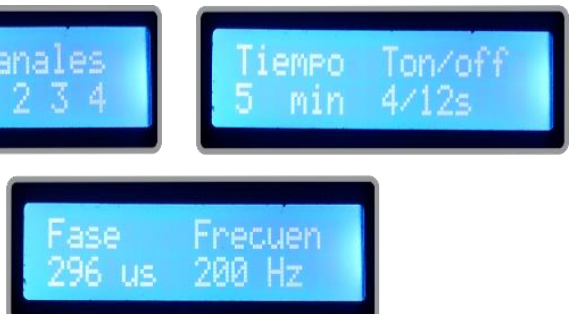

Figure 11. StimFace LCD screen information for passive therapy

Source: Authors

Now, we will show the images taken from the oscilloscope on the output of channel 1 in active therapy mode, with normalized load resistance in $1000-\Omega$ transcutaneous electrotherapy. Figure 12 shows the continuous pulse wave, characteristic of this type of therapy. Figure 13 shows the information deployed on the StimFace screen as the therapy takes place.

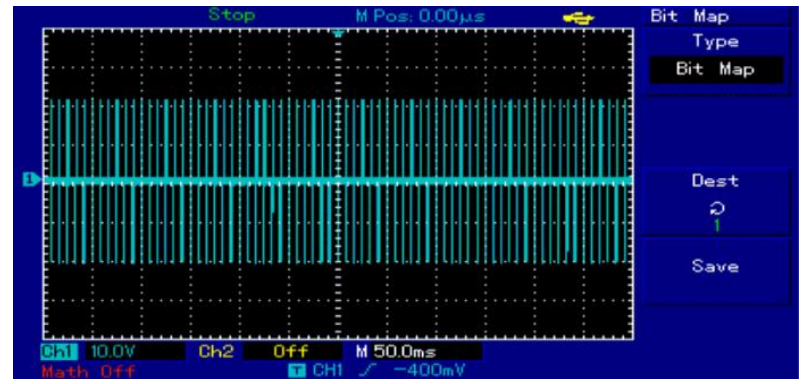

Figure 12. Continuous biphasic pulses for active therapy Source: Authors
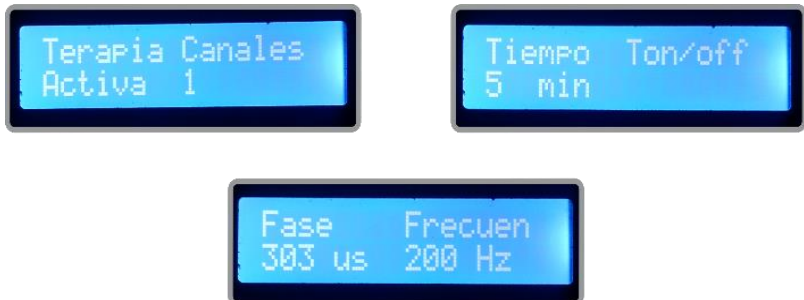

Figure 13. StimFace LCD screen information for active therapy

Source: Authors

\section{Discussion}

A functional prototype was constructed for electrotherapy applied in cases of facial palsy. The following stage of this research is the clinical validation of this technology developed from where we could obtain new adjustments in the equipment's control parameters. The final version of this equipment is totally projected with digital controls for all electrotherapy control parameters and more ergonomic industrial design of vanguard presentation, as shown in Figure 14.

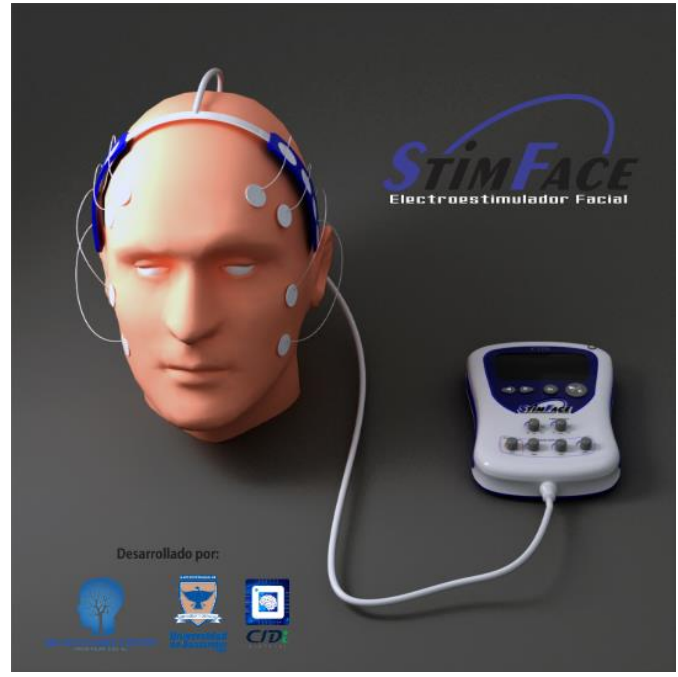

Figure 14. Prototype StimFace under development Source: Authors 


\section{TECCIENCLA}

\section{Conclusions}

A very versatile electrostimulation tool has been constructed, which complements traditional peripheral facial palsy rehabilitation processes, permitting clinical specialists to adjust a broad range of electrotherapeutic values, from current amplitude (without regard for the impedance of the tissues between electrodes), to the temporal characteristics of the current wave to adjust them to particular aspects of each patient, which will permit improving the effectiveness and efficiency of the respective treatment. The development of the StimFace facial electrotherapy prototype is a multidisciplinary research and development project involving efforts and contributions from various specialists. Starting with the equipment's users (clinical therapists), who determined the equipment's technical output characteristics, the contribution by electronic engineers to the hardware and software design and by the industrial designer, with contribution in usability and design of the housing of this first version. Upon employing a microcontroller, hardware on the equipment is substantially reduced and, hence, its size, consequently obtaining reduced costs of materials and greater ease of preventive and corrective maintenance. The development of this project demonstrates that in Colombia we are in the capacity of developing our own biomedical technologies to satisfy specific needs of the health sector, with high cost/benefit ratio.

\section{Acknowledgments}

The authors thank Dr. Omaira Buitrago, General Manager at the Neurotrauma Center, for allowing us to develop this project in her facilities and for having funded its construction.

\section{References}

[1] Centro de Investigación, Desarrollo e Innovación en Ingeniería de Rehabilitación (CIDi - IngeRehab), «Investigación en Ingeniería de Rehabilitación,» [En línea]. Available: http://www.neurotraumacenter.org/investigacion.html.

[2] T. Horia-Nicolai, «Intelligent Systems and Technologies in Rehabilitation Engineering,» CRC Press LCC, vol. 2001, pp. 3-13.

[3] Biblioteca Nacional de Medicina de EE.UU. Institutos Nacionales de la Salud: , «Parálisis de Bell,» [En línea]. Available: http://www.nlm.nih.gov/medlineplus/spanish/ency/article/000773. htm..

[4] Instituto Nacional de Trastornos Neurológicos y Accidentes Cerebrovasculares:, «Parálisis de Bell,»[En línea]. Available: http://espanol.ninds.nih.gov/trastornos/paralisis_de_bell.htm.

[5] F. F. Paula, H. Luis y M. Ramon, «Idiopathic peripheral facial paralysis treatment physic therapy versus prednisone,» Revista Médica del Instituto Mexicano del Seguro Social., vol. 36, n 3, pp. 217-221, 1998.

[6] Y. Xin, J. Jun, S. Steven, X. Qing y W. Guoxin, «A Blink Restoration System With Contralateral EMG Triggered Stimulation and Real-Time Artifact Blanking,» IEEE Transactions on Biomedical Circuits and Systems, vol. 7, n 2, pp. 140-148, 2013.

[7] A. Robinson, «Clinical Electrophysiology. Electrotherapy and Electrophysiologic Testing,» Lippincott, pp. 1-107, 2008.

[8] Neurotrauma Center, «Neurorehabilitación especializada de personas con enfermedades neurológicas y lesiones adquiridas de cerebro y médula espinal,» [En línea]. Available: http://www.neurotraumacenter.org/servicios-deneurorehabilitacion.html..

[9] Bioingeniería, « Sociedad Argentina de Ingeniería en Rehabilitación,» [En línea]. Available: http://www.sabi.org.ar/index.php?page=Rehabilitacion.

[10] C. Rory, «Rehabilitation Engineering Applied to Mobility and Manipulation,» pp. 1-6, 2006.

[11] D. Daniel, «NeuroEngineering,» CRC Press LCC, pp. 1-12, 2008.

[12] L. Blum, «Exploring Arduino. Tools and Techniques for Engineering Wizardry,» Wiley, pp. 13-62, 2013.

[13] Médica, Enciclopedia, «Enfermedades Neuronale,» [En línea]. Available: http://salud.doctissimo.es/enciclopediamedica/enfermedades-neurologicas/paralisis-facial.html.. 